\title{
Treatment of Anterior Open Bite with the Bimler Functional Appliance: Report of Three Cases
}

\author{
Ramirez-Yañez GO $^{1 *}$, Mahony $D^{2}$ and Bimler $B^{3}$ \\ ${ }^{1}$ Faculty of Dentistry, University of Manitoba, Winnipeg, Canada \\ ${ }^{2}$ Private Practice, Sydney, Australia \\ 3 International Stomatopedic Institute, Wiesbaden, Germany
}

*Corresponding author: German Ramirez-Yañez, Faculty of Dentistry, University of Manitoba, Winnipeg, Manitoba R3E 0W2, Canada, Tel: 1 289 430 5287; E-mail: ramirezy@cc.umanitoba.ca

Rec date: Jun 25, 2014, Acc date: Jul 25, 2014, Pub date: Jul 27, 2014

Copyright: (c) 2014 Ramirez-Yañez GO, et al. This is an open-access article distributed under the terms of the Creative Commons Attribution License, which permits unrestricted use, distribution, and reproduction in any medium, provided the original author and source are credited

\begin{abstract}
There is still controversy regarding the efficacy of functional appliances when treating malocclusion at an early age. Although a good outcome from treatment is important, the stability of the results over time becomes a major concern. This paper presents the results of three open bite cases treated with the Bimler type-A appliance in the mixed dentition. The open bite cases presented here demonstrate stability of the treatment results for more than 14 years without active retention after the active treatment period. A comparison between these cases and those performed with an elastic functional appliance, and the action of that appliance on tongue posture, are discussed. The cases presented in this paper support treating malocclusions at an early age with functional appliances. The features of the appliance chosen to treat an open bite early can be a key factor for the results and stability.
\end{abstract}

Keywords: Open Bite; Malocclusions; Functional appliances; Treatment stability

\section{Introduction}

The treatment of anterior open bite is a great challenge in orthodontics. A controversy exists about the ideal developmental stage at which an open bite should be treated. Some authors recommend starting treatment in the early mixed dentition with either fixed or removable functional appliances [1-3], while others endorse waiting and treating later in the permanent dentition [4-6].

The high incidence of relapse, even in those cases where treatment involves surgery, is one of the major concerns when treating open bites $[7,8]$. Tongue thrust is associated with this kind of malocclusion and has been reported as one of the major causes of relapse [9]. Although some reports tend to discourage the use of functional appliances $[6,10]$, treatments with functional techniques have been reported to produce beneficial skeletal outcomes. Functional appliances can stimulate a counterclockwise mandibular rotation, permit the mandible to continue growing in a more favorable direction and encourage a physiological posture of the tongue during oral functions [2,3,11-14]. In that context, early correction of open bites with functional appliances can lead to favorable and stable results [13-15,16-19]. However, the results of treatment may depend on the features of the functional appliance, which must be designed to deal with the mandibular rotation, to improve muscular activity and to correct tongue thrust $[11,12,14]$.

This paper reports the clinical and cephalometric modifications produced in three open bite patients treated with a functional appliance, the Bimler type-A (Figure 1). This appliance was proposed by Prof. Hans Peter Bimler in Germany, by the middle of the last century. All three cases were treated with the Bimler appliance only, delivering a new one every 6-8 months, and patients were instructed to wear it 24 hours per day, removing it from the mouth when eating. Treatment stability over 14 years or more is presented and discussed.

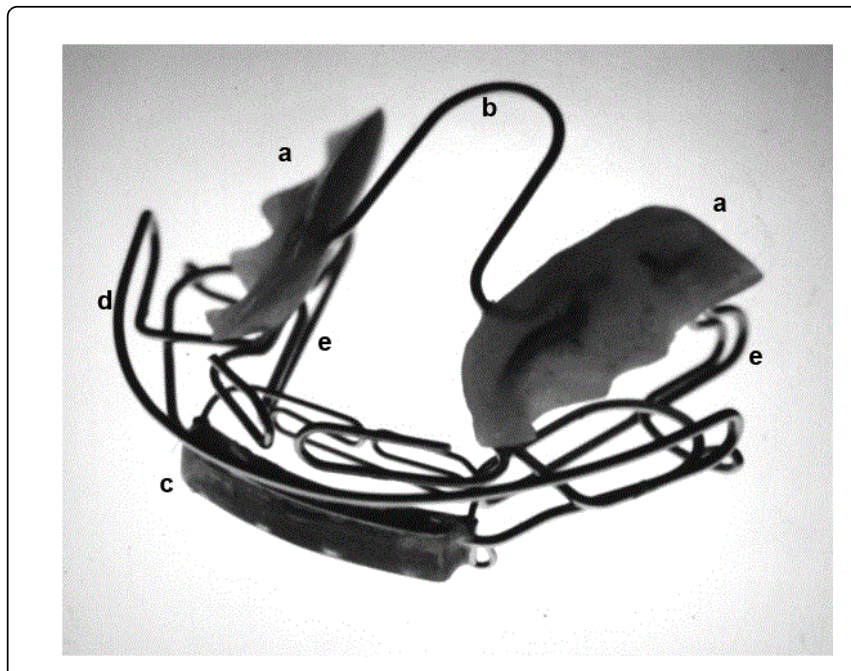

Figure 1: Picture showing the Bimler Type A appliance with is components: (a) acrylic plates; (b) coffin spring; (c) lower shield; (d) buccal bow; and, (e) dorsal arches

\section{Cases Report}

\section{Cephalometric measurements}

Cephalometric measurements before and after treatment were obtained as follows: Sella-Nasion-Point A (SNA), Sella-Nasion-Point B (SNB), Point A-Nasion-Point B (ANB), Gonion-Gnathion/Sella- 
Page 2 of 6

Nasion (GoGn/SN), Anterior Nasal Spine-Posterior Nasal Spine/SellaNasion (ANS-PNS/SN), ANS-PNS/Pterigoid Line (ANS-PNS/Pt), and, Gonion angle, subdivided as described by Jarabak into Gonion
Superior (GoS) and Gonion Inferior (GoI) angles. Values for the measured angles are presented in Table 1.

\begin{tabular}{|l|l|l|l|l|l|l|l|l|l|l|}
\hline & \multicolumn{3}{l}{ Case 1 } & \multicolumn{3}{l|}{ Case 2 } & \multicolumn{3}{l|}{ Case 3 } \\
\hline & Before & After & Diff. & Before & After & Diff. & Before & After & Diff. \\
\hline SNA & 82 & 83 & 1 & 82 & 82 & 0 & 81.5 & 81 & -0.5 \\
\hline SNB & 77 & 81 & 4 & 76 & 77 & 1 & 77 & 76 & -1 \\
\hline ANB & 5 & 2 & -3 & 6 & 5 & -1 & 5 & 5 & 5 & 0 \\
\hline GoGn/SN & 31 & 25 & -6 & 38 & 36 & -2 & 44 & 41 & -3 \\
\hline Maxilla/SN & 5 & 7 & 2 & 8 & 13 & 5 & 11 & 13 & 2 \\
\hline Upper Gonial & 55 & 55 & 0 & 59 & 55 & -4 & 51 & 58 & 7 \\
\hline Lower Gonial & 70 & 68 & -2 & 75 & 71 & -4 & 80 & 80 & 0 \\
\hline Gonial Angle & 125 & 123 & -2 & 134 & 126 & -8 & 131 & 138 & 7 \\
\hline Maxilla/Pt & 87 & 85 & -2 & 93 & 88 & -5 & 87.5 & 86 & -1.5 \\
\hline
\end{tabular}

Table 1: Values of the measured cephalometric angles of the three clinical cases presented in this report

\section{Case 1}
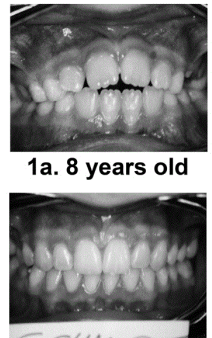

1b. 11 years old

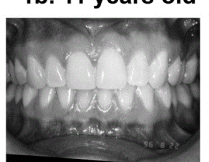

1c. 25 years old
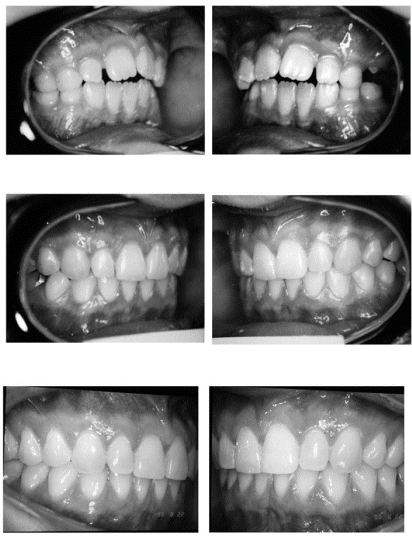

Figure 2: The figure shows the photos of case 1 when the patient was (a) eight years old; (b) eleven years old; and, (c) twenty-five years old. It also shows the drawings from the cephs before and after treatment $(\mathrm{a} \& \mathrm{~b})$. Notice the stability of the results after 14 years without any post-treatment retention

An eight year old girl presented for orthodontic treatment complaining she cannot touch her front teeth when closing her mouth. The clinical exam revealed a $3 \mathrm{~mm}$ negative overbite, $3.5 \mathrm{~mm}$ overjet and a Class II canine relationship (Figure 2a). Cephalometric measures showed a slight counterclockwise rotation of the maxilla, while the Gonial angle was within normal values. The mandible was retruded and the maxilla was in a normal relationship with the cranial base. Tongue thrust was observed on swallowing. The case was diagnosed as a skeletal Class II malocclusion with an open bite of dental origin, associated with tongue thrust. The objectives of treatment were to close the open bite, improve the sagittal position of the mandible and encourage a physiological position of the tongue at rest and swallowing, with the tip of the tongue postured on the incisive papillae region. This treatment plan involved the Bimler type-A appliance only.

After 36 months of treatment, the patient presented with the mandible postured forward and the open bite closed (Figure 2b). Tongue thrust was corrected and the tongue was resting in a physiological position. Teeth were aligned and the dental overbite and overjet were within normal values. Cephalometrics at that point revealed an increase of SNB of four degrees with a consequent reduction of $\mathrm{ANB}$ of three degrees. SNA was not modified by the treatment. Go-Gn/SN reduced six degrees, which was interpreted as a counterclockwise mandibular rotation. Concurrently, a slight rotation of the mandibular body was shown as the GoI angle reduced two degrees. ANS-PNS/SN increased two degrees, confirming the maxilla rotated downward. Since the objectives of treatment were achieved at that point, the appliance was discontinued. The patient was followed up over a 14 year period, with the overbite and overjet showing no variation and the tooth alignment maintained (Figure 2c).

\section{Case 2}

A nine year old girl presented with an open bite $(3 \mathrm{~mm}$ negative overbite) and normal overjet. Clinical examination revealed a Class I canine relationship, under-erupted mandibular incisors and tongue thrust (Figure 3a). Cephalometrics exposed a reduced angle between the cranial base and the maxilla (ANS-PNS/SN) and an increased Gonial angle. Sagittal maxillo-mandibular relationship was within normal values. The Upper Gonial angle was increased, indicating a posterior rotation of the mandibular ramus. The Lower Gonial angle value was within the normal parameters. The case was diagnosed as a Class I malocclusion associated with a combined skeletal and dental open bite, due to mouth breathing and tongue thrust. Treatment was planned with the Bimler type-A appliance. The objectives of the treatment were to close the open bite without affecting the sagittal 
maxillo-mandibular relationship. Treatment also aimed to promote physiological tongue position at rest and swallowing.
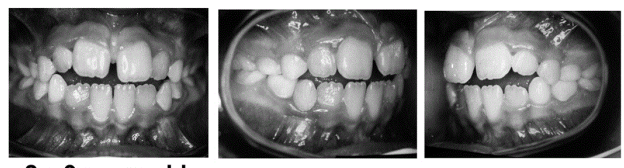

2a. 9 years old
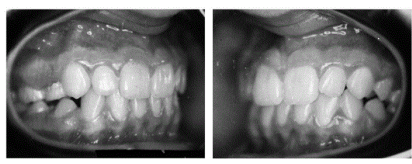

2b. 11 years old
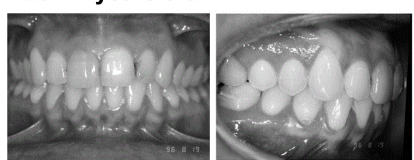

2c. 29 years old

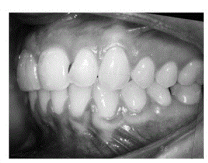

Figure 3: The figure shows the photos of case 2 when the patient was (a) nine years old; (b) eleven years old; and, (c) twenty-nine years old. It also shows the drawings from the cephs before and after treatment $(\mathrm{a} \& \mathrm{~b})$. Notice the stability of the results after 18 years without using any retention

After two years of treatment, the objectives were attained and active treatment was stopped. Clinically the open bite was closed and the mandibular incisors leveled with the posterior teeth (Figure 3b). Cephalometric measurements revealed that Upper and Lower Gonial angles reduced four degrees each, with no modifications in the SNA, SNB or ANB angles. The maxilla rotated downward as the ANS$\mathrm{PNS} / \mathrm{SN}$ angle increased five degrees correlating with a similar reduction in the ANS-PNS/Pt angle. Those measurements suggest an upward rotation of the mandible, particularly of the mandibular body, accompanied by a downward rotation of the maxilla. In this case, treatment improved the vertical relationship between maxilla and mandible without affecting their sagittal relationship. The patient did not wear a retainer after the active treatment. Eighteen years of follow up showed no relapse of the open bite or tooth misalignment (Figure $3 c)$.

\section{Case 3}

An Eight year old girl was referred for treatment because an anterior open bite. The clinical exam revealed a $3 \mathrm{~mm}$ overbite and an edge-to-edge relationship at the incisors. The canine's relationship was Class III on the right and Class I on the left. Mandibular incisors were under-erupted. (Figure 4a) Cephalometric measurements exposed a tendency to skeletal Class II malocclusion as the SNB angle was reduced and the ANB angle was slightly increased. The Gonial and the Go-Gn/SN angles were increased indicating a clockwise rotation of the mandibular corpus. The ANS-PNS/Pt angle was reduced, suggesting the maxilla rotated downward. The case was diagnosed as a Class II skeletal malocclusion associated with a combined skeletal and dental open bite due to tongue thrust.

As with the two previous cases, this patient was treated only with the Bimler Type A appliance. The objectives of the treatment were to close the open bite and improve the overjet and overbite by means of positioning the mandible slightly forward and guiding the eruption of the incisors into the correct position. The prognosis in this case was guarded since a serial extraction protocol had been initiated on the upper dental arch by the previous dentist with extraction of the first premolars.

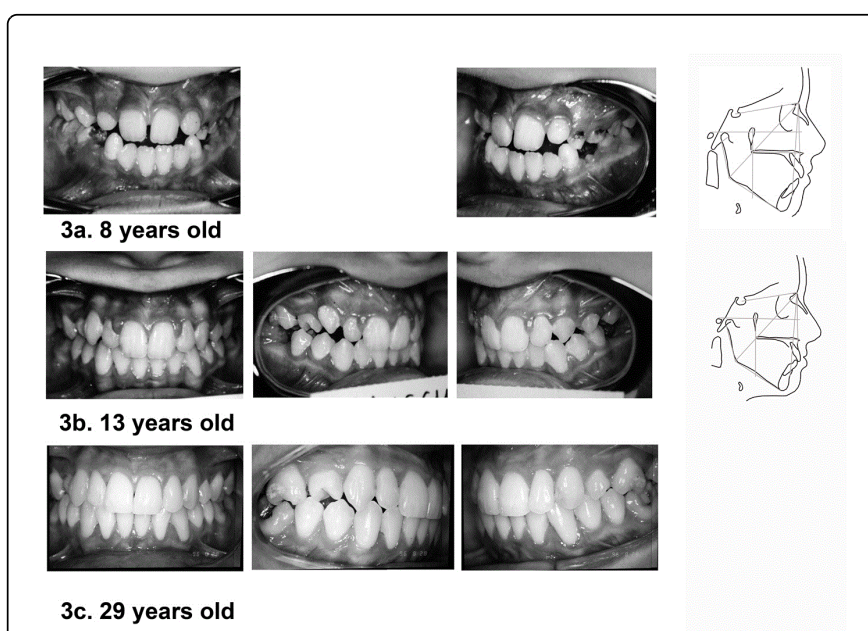

Figure 4: The figure shows the photos of case 3 when the patient was (a) eight years old; (b) thirteen years old; and, (c) twenty-nine years old. It also shows the drawings from the cephs before and after treatment $(\mathrm{a} \& \mathrm{~b})$. Notice the stability of the results after 16 years follow up with no retention

Active treatment with the functional appliance ended when the patient was 12 years old, totaling four years of active treatment (Figure $4 \mathrm{~b})$. Clinically, the open bite was closed and the overjet and overbite were within normal values. No skeletal sagittal changes were measurable at the end of treatment. Nevertheless, cephalometry computed an improvement in the GoGn/SN angle, which reduced three degrees. The ANS-PNS/Pt angle reduced one and a half degrees. Although those latter values suggested the mandibular body tended to rotate into a counterclockwise direction and the maxilla into a clockwise direction, an increase of seven degrees in the Gonial angle inferred a continued vertical growth pattern. Regardless of the adverse cephalometric results in the Gonial angle, the clinical results accounted for a successful treatment of the open bite.

The patient discontinued using the functional appliance at that point. Fixed orthodontic treatment was suggested to de-rotate the upper right second premolar (Figure 4c), but,the patient was happy with the results and did not consider having brackets for that minor adjustment. No retention device was worn afterwards. A sixteen year follow up showed no relapse of the open bite. The rotated upper premolar stayed in the same position over the follow up period.

\section{Discussion}

A controversy still exists regarding the efficacy and long-term stability of functional appliances when treating malocclusions. Three cases presented here have shown that the Bimler type- $A$ is an alternative for treating sagittal and vertical deviations of the dental occlusion. Furthermore, these clinical cases showed stable clinical results after a period of 14 years or more.

A remarkable finding is that the Bimler type-A appliance stimulated a favorable rotation of the mandible. That effect was quantified as 
there was a reduction in the values of the GoGN/SN and the Inferior Gonial angles caused by the treatment in two of the three cases presented here. In open bite patients, the tongue at rest tends to be positioned between the upper and lower incisors and thrusting forward on swallowing (Figure 5a) [9]. These patients had tongue thrust which was not present at the end of the active treatment with the functional appliance. That positive outcome could have resulted from a change in the posture of the tongue at rest and swallowing stimulated by the functional appliance [17].

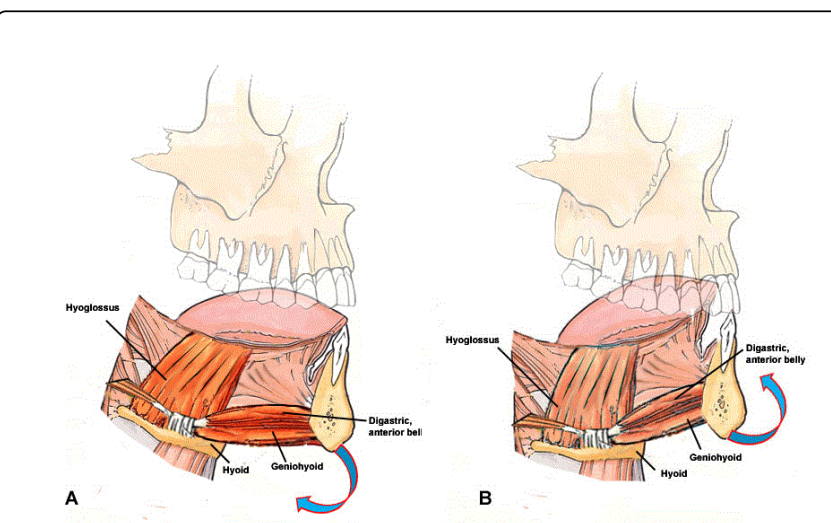

Figure 5: (A) Diagram representing the position of the tongue and the hyperactivity of the muscles attaching the tongue and the mandible to the hyoid bone in open bite. A situation like that favours a clock-wise rotation of the mandible. (B) Diagram representing the relaxation of the muscles attaching the tongue and mandible to the hyoid bone when the tip of the tongue is placed on the incisive papilla region. This change in the position of the tongue favours a counter clock-wise rotation of the mandible

In order to explain how the Bimler type A can stimulate mandibular rotation by bringing the tongue to a more physiological position, it is necessary to understand how the tongue, the supra-hyoid muscles and the mandible work together. Thus, based on the anatomy of the tongue, a hypothesis on the effects of the functional appliance from tongue position and function is presented

One of the major muscles of the tongue, the hyoglossus muscle, attaches to the hyoid bone, which also serves as insertion for the anterior digastric and the geniohyoid muscles. The latter two muscles simultaneously attach to the posterior-inferior border of the mandibular symphysis (Figure 5). When the tongue's tip is positioned between the maxillary and mandibular incisors teeth, the dorsum of the tongue is moved upward and forward. That pulls the hyoid bone upward and backward because the hyoglossus muscle has to contract (Figure 5a). A backward position of the hyoid bone stretches the anterior digastrics and the geniohyoid muscles pulling the mandibular symphysis down and backward. That stimulates the mandibular body to rotate in a clockwise direction (Figure 5a).

The functional appliance can counteract that negative effect by positioning the tip of the tongue on the incisive papilla, permitting the dorsum of the tongue to displace backward, relaxing the hyoglossus muscle and reducing the traction on the hyoid bone. In such a situation, the hyoid bone is allowed to reach a more physiological position (Figure $5 \mathrm{~b}$ ), reducing the down and backward pulling exerted on the mandibular symphisis by the anterior digastric and geniohyoid muscles. In this way, the effects produced by the non-physiological position of the tongue between the incisors teeth before treatment can be controlled. That would explain the counter-clockwise mandibular rotation observed in the first two clinical cases presented here. That favorable rotation of the mandible in open bite cases has also been reported with other functional appliances, such as the Frankel's Functional Regulator [20,21]. Randomized clinical studies with functional appliances evaluating tongue posture with ultrasound or cinefluorography are required to test this hypothesis.

Myofunctional therapy has shown to improve the results when combined with orthodontics $[22,23]$. As reported here, the causes of the open bite in the three cases were tongue thrust and mouth breathing. In situations like that, myofunctional therapy could be considered beside the functional treatment to improve the stability of the treatment and reduced the time required to treat the malocclusion.

Case three was more complicated and the prognosis was guarded as it was a skeletal open bite associated with an increased value for the Gonial angle. Plus, the two first premolars were already extracted when the patient was accepted for treatment. Regardless of those adverse issues, clinical success was achieved and no relapse was observed during the follow up period of 16 years. An interesting point in this case was that the clockwise mandibular rotation continued during the treatment period. The Gonial angle's value was higher at the end of the active treatment. In that context, the dolichofacial morphological pattern was maintained. A recent study reported that the morphological facial pattern may be maintained after mouth breathing rehabilitation, even though mandibular structural changes are produced [24]. The results of our last case agree with that study. The authors suggest that that physiological positioning of the tongue achieved at the end of the active treatment helped to prevent relapse regardless of the craniofacial growing pattern. In that context, the influence of the soft tissues on mandibular development should be considered critical for the stability of the results after treatment [25].

Treatment efficiency and stability are two of the issues highly discussed regarding functional appliances. Systematic reviews and meta-analysis evaluating the efficiency of functional appliances to treat malocclusions do not show the reality of the results frequently observed by the clinicians, who in many cases get similar results to those presented here. Most of the clinical studies reported in the literature have been performed with rigid and bulky functional appliances (eg. Bionator, Monoblock, Twin-block, etc.). Those rigid appliances are used to improve the sagittal posture of the mandible. They maintain the mandible in a forwarded position, and thus, they produce a splint effect. Although the Bimler appliance similarly moves the mandible forward, it has less acrylic with most of its structure being built with wires. That feature converts the Bimler into a more elastic appliance, modifying the posture of the mandible in a sagittal direction and giving some degree of freedom for vertical rotation [26]. That freedom given to the mandible permits the counter-clockwise rotation by stimulating a better tongue position. Therefore, a stimulus on the masticatory muscles making them able to maintain the mandible in a new sagittal relationship and the counter-clockwise mandibular rotation observed accounted for the successful result in two of the three cases presented here.

Another matter which needs to be viewed is the search for mandibular growth. When the efficacy of functional appliances has been evaluated by different authors, most of the studies look for mandibular growth. Changing the posture of the mandible requires a sequence of cellular events targeting increased bone formation, and as a result, mandibular growth $[27,28]$. That concept has probably misled 
the dental community, who expect mandibular growth to be a result of or response to functional appliances. However, successful results can become from other phenomena. Functional changes occur first in the muscles. Bone remodeling occurs as a consequence. Therefore, changes in muscular activity are responsible for holding the mandible in the new position, which will then change mandibular growth direction $[29,30]$. In that context, the concepts of the effect of functional appliances on mandibular growth have to be reviewed. Effects result first, from an adaptive response in the muscles holding the mandible $[17,29]$, causing variation in the loads on the mandibular bone, which later would lead to mandibular growth [30].

The effect of the treatment with a functional appliance on the TMJ and the mandibular fossa should also be considered. Treatment with functional appliances can produce extensive remodeling and anterior relocation of the mandibular fossa [31]. Functional treatment changes the position of the mandibular condyle within the mandibular fossa [32]. Thus, there can be changes in the posture of the mandible without modifying its size. Studies evaluating the efficacy of functional appliances must consider those changes too. In other words, the search for mandibular growth must not be limited to looking at the mandible alone, but also consider a bigger view of all craniofacial structures in all dimensions of space.

The three clinical cases presented in this report showed a long-term stability. Similar results have been reported with other functional appliances, such as Frankel's Functional Regulator [33]. The features of the Bimler type-A permit a more comfortable change in the position of the mandible, inducing a counter-clockwise mandibular rotation and a physiological position of the tongue at rest and with swallowing. We hypothesize that this accounts for the successful results and the stability over a long period. This clinical case report agrees with those studies asserting that different features in functional appliances may lead to different results, as well as may influence the efficacy and longterm stability of the treatment [15,34-36]. Future studies evaluating the efficacy of functional appliances should consider the differences in appliances and do not generalize to all of them the results from another appliance.

\section{Conclusions}

This report presented three clinical cases where anterior open bite was successfully treated with the Bimler type-A appliance. It was observed that the functional appliance produced a net mandibular advancement and favorable rotation possibly due to a better position of the tongue. It was also shown that the results obtained with the functional treatment remained stable for 14 years or more. Study of the efficacy of functional appliance treatment must involve an evaluation of the tridimensional changes in the posture of the mandible, changes in masticatory muscle activity and TMJ modeling, rather than only looking for mandibular growth.

\section{References}

1. Keski-Nisula K, Hernesniemi R, Heiskanen M, Keski-Nisula L, Varrela J (2008) Orthodontic intervention in the early mixed dentition: a prospective, controlled study on the effects of the eruption guidance appliance. Am J Orthod Dentofacial Orthop 133: 254-260.

2. Cinsar A, Alagha AR, Akyalçin S (2007) Skeletal open bite correction with rapid molar intruder appliance in growing individuals. Angle Orthod 77: 632-639.

3. Erbay E, Uğur T, Ulgen M (1995) The effects of Frankel's function regulator (FR-4) therapy on the treatment of Angle Class I skeletal anterior open bite malocclusion. Am J Orthod Dentofacial Orthop 108: 9-21.

4. Denny JM, Weiskircher MA, Dorminey JC (2007) Anterior open bite and overjet treated with camouflage therapy. Am J Orthod Dentofacial Orthop 131: 670-678.

5. Hans MG, Teng CM, Liao CC, Chen YH, Yang CY (2007) An evidencebased approach to treatment of open bite and deep bite: case reports. World J Orthod 8: 45-64.

6. Tulloch JF, Proffit WR, Phillips C (2004) Outcomes in a 2-phase randomized clinical trial of early Class II treatment. Am J Orthod Dentofacial Orthop 125: 657-667.

7. Katsaros C, Berg R (1993) Anterior open bite malocclusion: a follow-up study of orthodontic treatment effects. Eur J Orthod 15: 273-280.

8. Espeland L, Dowling PA, Mobarak KA, Stenvik A (2008) Three-year stability of open-bite correction by 1-piece maxillary osteotomy. Am J Orthod Dentofacial Orthop 134: 60-66.

9. Cayley AS, Tindall AP, Sampson WJ, Butcher AR (2000) Electropalatographic and cephalometric assessment of tongue function in open bite and non-open bite subjects. Eur J Orthod 22: 463-474.

10. Wijayaratne D, Harkness M, Herbison P (2000) Functional appliance treatment assessed using the PAR index. Aust Orthod J 16: 118-126.

11. Sankey WL, Buschang PH, English J, Owen AH 3rd (2000) Early treatment of vertical skeletal dysplasia: the hyperdivergent phenotype. Am J Orthod Dentofacial Orthop 118: 317-327.

12. Arat M, Iseri H (1992) Orthodontic and orthopaedic approach in the treatment of skeletal open bite. Eur J Orthod 14: 207-215.

13. Berger JL, Pangrazio-Kulbersh V, George C, Kaczynski R (2005) Longterm comparison of treatment outcome and stability of Class II patients treated with functional appliances versus bilateral sagittal split ramus osteotomy. Am J Orthod Dentofacial Orthop 127: 451-464.

14. De souza DR, Semechini TA, Kroll LB, Berzin F (2007) Oral myofunctional and electromyographic evaluation of the anterior suprahyoid muscles and tongue thrust in patients with Class II/1 malocclusion submitted to first premolar extraction. J Appl Oral Sci 15: 24-28.

15. Cozza P, Baccetti T, Franchi L, De Toffol L, McNamara JA Jr (2006) Mandibular changes produced by functional appliances in Class II malocclusion: a systematic review. Am J Orthod Dentofacial Orthop 129: 599.

16. Muntean R, Komposch G, Steegmayer-Gilde G (2007) Long-term Stability of Extraction Therapy in Anterior Open Bite. A Case Report. J Orofac Orthop 68: 413-422.

17. Leung DK, Hägg U (2001) An electromyographic investigation of the first six months of progressive mandibular advancement of the Herbst appliance in adolescents. Angle Orthod 71: 177-184.

18. Adrianopoulos MV, Hanson ML (1987) Tongue-thrust and the stability of overjet correction. Angle Orthod 57: 121-135.

19. Akkaya S, Haydar S, Bilir E (2000) Effects of spring-loaded posterior biteblock appliance on masticatory muscles. Am J Orthod Dentofacial Orthop 118: 179-183.

20. Yassaei S, Bahrololoomi Z, Sorush M (2007) Changes of tongue position and oropharynx following treatment with functional appliance. J Clin Pediatr Dent 31: 287-290.

21. Baik HS, Jee SH, Lee KJ, Oh TK (2004) Treatment effects of Fränkel functional regulator III in children with class III malocclusions. Am J Orthod Dentofacial Orthop 125: 294-301.

22. Cabrera Mde C, Cabrera CA, de Freitas KM, Janson G, de Freitas MR (2010) Lateral open bite: treatment and stability..Am J Orthod Dentofacial Orthop 137: 701-11.

23. Celli D, Gasperoni E, Deli R (2007) Long-term outcome in a patient with a dentoskeletal open-bite malocclusion treated without extraction. World J Orthod 8: 344-356.

24. Mattar SE, Valera FC, Faria G, Matsumoto MA, Anselmo-Lima WT (2011) Changes in facial morphology after adenotonsillectomy in mouthbreathing children. Int J Paediatr Dent 21: 389-396. 
Citation: Ramirez-Yañez GO, Mahony D, Bimler B (2014) Treatment of Anterior Open Bite with the Bimler Functional Appliance: Report of Three

Page 6 of 6

25. Ackerman JL, Profitt WR, Sarver DM (1999) The emerging soft tissue paradigm in orthodontic diagnosis and treatment planning. Clin Orthod Res 2: 49-52.

26. Simoes WA, Petrovic A, Stutzmann J (1992) Modus operandi of Planas' appliance. J Clin Pediatr Dent 16: 79-85.

27. Rabie AB, Leung FY, Chayanupatkul A, Hägg U (2002) The correlation between neovascularization and bone formation in the condyle during forward mandibular positioning. Angle Orthod 72: 431-438.

28. Petrovic A (1994) Auxologic categorization and chronobiologic specification for the choice of appropriate orthodontic treatment. Am J Orthod Dentofacial Orthop 105: 192-205.

29. Ulusoy C, Darendeliler N (2008) Effect of Class II activator and Class II activator high-pull headgear combination on the mandible: a 3 dimensional finite element stress analysis study. Am J Orthod Dentofacial Orthop 133: 490.

30. Frost HM (2004) A 2003 update of bone physiology and Wolff's Law for clinicians. Angle Orthod 74: 3-15.

31. Woodside DG, Metaxas A, Altuna G (1987) The influence of functional appliance therapy on glenoid fossa remodeling. Am J Orthod Dentofacial Orthop 92: 181-198.
32. Kinzinger GS, Roth A, Gülden N, Bücker A, Diedrich PR (2006) Effects of orthodontic treatment with fixed functional orthopaedic appliances on the disc-condyle relationship in the temporomandibular joint: a magnetic resonance imaging study (Part II). Dentomaxillofac Radiol 35: 347-356.

33. Freeman DC, McNamara JA Jr, Baccetti T, Franchi L, Fränkel C (2009) Long-term treatment effects of the FR-2 appliance of Fränkel. Am J Orthod Dentofacial Orthop 135: 570.

34. Shen G, Hägg U, Darendeliler M (2005) Skeletal effects of bite jumping therapy on the mandible - removable vs. fixed functional appliances. Orthod Craniofac Res 8: 2-10.

35. Hägg U, Rabie AB, Bendeus M, Wong RW, Wey MC, et al. (2008) Condylar growth and mandibular positioning with stepwise vs maximum advancement. Am J Orthod Dentofacial Orthop 134: 525-536.

36. Rabie AB, Al-Kalaly A (2008) Does the degree of advancement during functional appliance therapy matter? Eur J Orthod 30: 274-282. 